\title{
The computational methods in the development of a novel multianalyte calibration technique for potentiometric integrated sensors systems
}

\author{
Marcin Urbanowicz ${ }^{1}$ (D) Dorota G. Pijanowska ${ }^{1} \cdot$ Artur Jasiński $^{2} \cdot$ Maria Bocheńska $^{2}$ \\ Received: 6 May 2019 / Revised: 11 June 2019 / Accepted: 13 June 2019 / Published online: 25 June 2019 \\ (C) The Author(s) 2019
}

\begin{abstract}
In recent years, integration and miniaturization of ion-selective electrodes (ISEs) have brought many benefits resulting in the possibility of simultaneous determination of the ions concentration in small volume samples. One of the key problems related to the preparation of potentiometric integrated sensors systems (PISSs) is a calibration procedure due to the necessity to calibrate each particular sensor separately. The main aim of the research was to develop a novel calibration method for PISSs fabricated with the use of an all-solid-state technology, which has been compared with other types of sensor calibration technique. The proposed algorithm concerns the method of calibration solutions composition determination for miniature ion-selective sensors before measuring in biological samples especially human saliva samples. This article also compares the parameters of ionselective sensors for two types of PISSs, including ISEs based on gold (Au) and glassy carbon (GC) electrodes. In addition, a series of measurements was performed using PISS with Au-ISEs in samples of human saliva, which were preceded by different types of sensor calibration and compared with the results obtained with the clinical analyzer. Moreover, the effect of the viscosity of calibration solutions on the ISE parameters and the lifetime of the sensors were investigated.
\end{abstract}

Keywords Multianalyte calibration $\cdot$ ISE lifetime $\cdot$ Potentiometric integrated sensors systems $\cdot$ Calibration methods

\section{Introduction}

Ion-selective electrodes have been invariably very popular for many years as a convenient and useful tool for determination of ions concentration [1]. The use of new materials and techniques for the production of ISE has created new opportunities in the construction and integration of these sensors. An example of this type of tools is the miniature sensors platforms, fabricated in the all-solid-state technology [2-8], equipped with a miniature reference electrode without internal liquid electrolyte. The small size of potentiometric sensors, use of

Marcin Urbanowicz

murbanowicz@ibib.waw.pl

1 Nalecz Institute of Biocybernetics and Biomedical Engineering Polish Academy of Sciences, Ks. Trojdena 4, 02-109 Warsaw, Poland

2 Department of Chemistry and Technology of Functional Materials, Chemical Faculty, Gdańsk University of Technology, Narutowicza 11/12, 80-233 Gdańsk, Poland readily available and inexpensive materials allow for selective analysis in a small sample volume $[9,10]$. One of the major problems related to the recent use of the potentiometric integrated sensors systems (PISSs) is calibration [11]. This problem is associated to the presence of several sensors selective to different ions, (e.g., $\mathrm{Na}^{+}, \mathrm{K}^{+}, \mathrm{Cl}^{-}$) [12]. The main problem related to sensors' integration is establishing a procedure for simultaneous calibration of the sensors that ensure multiple measurements of analytes. Correct calibration is particularly important in clinical measurements, where the ions concentration's measurement ranges are narrow then, a small error may affect the correct assessment of the patient's health condition [13]. The challenge in the calibration of ion-selective sensors is to consider the influence of interfering substances that can generate errors during the measurements [14]. Over the years, ISE's calibration methods have evolved from the simplest calibration techniques, using simple solutions that contained only the measured ion [15], through continuous and injection calibration $[16,17]$, to methods using mathematical models to design calibration solutions [18].

In order to minimize analytical errors, various procedures are used to prevent them. In the case of $\mathrm{Pb}^{2+}$ selective sensors 
made in solid state technology, multiple calibrations to determine the optimal measurement time were used [19]. This calibration technique was particularly advantageous when the concentration of the main ion was approximately equal to the concentration of the interfering ion. Another important aspect regarding the calibration of ion-selective sensors is the measurement environment. The presence of proteins and variable $\mathrm{pH}$ of the sample may negatively affect the ISE response [20]. An example of leveling the effect of the protein presence in a sample is the use of physical adsorption of protein to the membrane, which positively affected the Pb-ISE measurement range by using the synergistic effect of lead ion complexation by BSA [21]. The ellipsometry studies have also confirmed that the biofouling phenomena depend on the composition of the ion-selective membrane and the type of ion-electron transducer used in favor of PEDOT:PSS [21].

The potentiometric response of ISE is proportional to the logarithm of the ions' activity contained in the aqueous solution according to the Nernst (1) and Nikolsky-Eissenman (2) equations:

$E=E^{0}+R T z^{-1} F^{-1} \cdot \ln \left(a_{i}\right)$

$E=E^{0}+S \cdot \log \left(a_{\mathrm{i}}+\Sigma K_{\mathrm{ij}}^{\mathrm{pot}} \cdot a_{\mathrm{j}}^{\mathrm{zi} / 2 \mathrm{j}}+L\right)$

where: $E$-electrode potential; $E^{0} E^{0}$ —electrode standard potential $[\mathrm{mV}] ; R-\mathrm{gas}$ constant $\left[\mathrm{J} / \mathrm{mol} \mathrm{K}^{-1} \frac{J}{\mathrm{~mol} \cdot \mathrm{K}}\right]$; $T$-temperature $[\mathrm{K}] ; F$-Faraday constant $[\mathrm{C} / \mathrm{mol}] ; \mathrm{z}_{\mathrm{i}}$ and $z_{\mathrm{j}}$ - the charges of the primary and interfering ions, respectively; $a_{\mathrm{i}}$-activity of the primary ion; $S$ - sensitivity $[\mathrm{mV} / \mathrm{dec}]$; $a_{\mathrm{j}}$-activity of the interfering ion; $K_{\mathrm{ij}}{ }^{\text {pot }}$ - selectivity coefficient; $L$-limit of detection [ $\left.\mathrm{mol} \mathrm{dm}^{-3}\right]$.

According to the extended Debye-Hückel equation (3), in aqueous solutions with ionic strength above $0.1 \mathrm{~mol} \mathrm{dm}^{-3}$ [22], the activity value cannot be directly approximated to the concentration value $(c)$. This is particularly important due to description of the ISEs work model.

$\log \left(\gamma_{ \pm}\right)=\left|z_{\mathrm{i}+} z_{\mathrm{i}-}\right| \mathrm{AI}^{0.5} \cdot\left(1+a \mathrm{~B} \mathrm{BI}^{0.5}\right)^{-1}$

where, $\gamma_{ \pm}$-average ion activity coefficient; $z_{\mathrm{i}+}, z_{\mathrm{i}-}$-charges of primary cation and anion, respectively; $A, B$ - constant depending on the temperature and dielectric constant of the solvent; $\stackrel{a}{a-e f f e c t i v e}$ diameter of the hydrated ion; $I$-ionic strength.

In the case of multicomponent solutions, an important element in their design is controlling the ionic strength $(I)$, which describes the strength of ionic interactions (4) in the solution.

$I=1.5 \Sigma_{\mathrm{i}=1} c_{\mathrm{i}} z_{\mathrm{i}}^{2}$

When designing calibration solutions dedicated to determining the concentration of selected ions in the sample, the abovementioned relationships should be taken into account, as well as: the required selectivity coefficient, $K_{\mathrm{ij}}{ }^{\text {pot }}$ (req), (5), where $P_{\mathrm{ij}}$ is a value describing the permissible relative error in the measurement of the main ion activity with respect to the interfering ion.

$K_{\mathrm{ij}}{ }_{(\mathrm{peq})}^{\mathrm{pot}}=a_{i} \cdot\left(a_{j}^{\mathrm{zi} / \mathrm{zj}}\right)^{-1} \cdot\left(0.01 P_{\mathrm{ij}}\right)^{\mathrm{zi} / \mathrm{zj}}$

The required selectivity coefficients calculated on the basis of Eq. (5) can be compared with determined selectivity coefficients with simultaneous ionic strength control. The presented algorithm allows one to select the composition of calibration solutions in such a way that $\left|\log \left(K_{\mathrm{ij}}{ }^{\text {pot }}\right)\right| \geq \mid \log$ $\left(K_{\mathrm{ij}(\mathrm{req})}{ }^{\mathrm{pot}}\right) \mid$ and $I_{\text {calculated }} \approx I_{\text {sample. }}$. The direct influence of ionic strength is manifested, among others, in the change of ion activity coefficients. The main problem in the design of calibration solutions is to maintain a constant value of ionic strength adequate for the sample and the calibration solutions [23].

One of the parameters describing rheological properties of body fluids is dynamic viscosity [24]. At $37^{\circ} \mathrm{C}$, human blood has a dynamic viscosity of $3.5 \mathrm{mPa} \cdot \mathrm{s}$, and for saliva, this value is much more varied and ranges from 1.3 to $2.5 \mathrm{mPa} \cdot \mathrm{s}$ [25-27]. For comparison, the viscosity of water at this temperature is 0.7 $\mathrm{mPa} \cdot \mathrm{s}$. Since the high viscosity of body fluids might be a factor affecting potentiometric sensors response, for example through hindered ions migration and difficult washing of the membrane, then this problem becomes part of this research.

The aim of our research was to compare different methods of PISSs ion-selective sensors' calibration in order to measure precision. In our research, calibration solutions with varying complexity of their composition were utilized. The obtained results suggest that maintaining a small difference in ionic strength between the sample and the calibration solutions positively affects the precision of determination of analytes concentration.

\section{Experimental}

\section{Chemicals}

To perform the different ion-selective membranes, the following ionophores were used: $p$-tert-butylcalix[4]arenetetraacetic acid tetraethyl ester (sodium ionophore X), valinomycin (potassium ionophore I), N,N-dicyclohexyl-N ',N'-dioctyldecyl-3-oxapentane-diamide (calcium ionophore IV), $N, N^{\prime \prime}$ - octamethylene-bis $\left(N^{\prime}\right.$ - heptyl- $N^{\prime}$ methylmalonamide) (magnesium ionophore III), tridodecylamine (hydrogen ionophore I) all purchased from Sigma Aldrich, and tetrakis-(4-triphenylphosphoniumbutoxy)-p-tert-butylcalix[4] arene tetrathiocyanate (thiocyanate ionophore) obtained by synthesis $[28,29]$. The exact 
percentage of membrane's composition is given in Table 1. The other membranes components were as follows: poly (vinyl chloride) (PVC of high molecular weight), bis-(2ethylhexyl)-sebacate (DOS) $\geq 97 \%$, o-nitrophenyl octyl ether $(o-\mathrm{NPOE}) \geq 99 \%$, chloroparaffin $60 \%$ chlorine basis, potassium tetrakis $(p$-chlorophenyl) borate $(\mathrm{KTpClPB}) \geq 97 \%$; tridodecylmethylammonium chloride (TDMACl). For preparation of calibration solutions $\mathrm{NaCl} \geq 99.9 \%, \mathrm{KCl} \geq 99.5 \%$, $\mathrm{CaCl}_{2} \cdot 6 \mathrm{H}_{2} \mathrm{O} \geq 99 \%, \mathrm{MgCl}_{2} \cdot 6 \mathrm{H}_{2} \mathrm{O} \geq 99.5 \%, \mathrm{KSCN} \geq 99.5 \%$, $\mathrm{CH}_{3} \mathrm{COONa} \geq 99.5 \%, \mathrm{CH}_{3} \mathrm{COOLi} \cdot 2 \mathrm{H}_{2} \mathrm{O} \geq 99 \%, \mathrm{KOH}$, methanol, pH buffer $(5.00 \pm 0.05,7.00 \pm 0.05,9.00 \pm 0.05)$, glycerol $>99.5 \%$ purchased from Avantor Performance Materials, Poland S.A. and a freshly deionized water obtained by the reverse osmosis (RO) from Hydro-Lab-PL station $(\leq$ $0.1 \mu \mathrm{S} / \mathrm{cm})$ were used.

\section{Equipments}

The integrated sensors systems GC-PISS and Au-PISS were fabricated with the use of materials such as glassy carbon (GC) and gold, respectively (Fig. 1). The GC-PISS was equipped with $\mathrm{Na}^{+}, \mathrm{K}^{+}$, and $\mathrm{Ca}^{2+}$ selective membranes. The $\mathrm{Au}-\mathrm{PISS}$ was prepared in two variants. The first variant consisted of sensors for determination of $\mathrm{Na}^{+}, \mathrm{K}^{+}, \mathrm{Ca}^{2+}$, and $\mathrm{Mg}^{2+}$ ions, while the second one contained selective electrodes for $\mathrm{Cl}^{-}, \mathrm{SCN}^{-}$, and $\mathrm{H}^{+}$ions. The analytically sensitive elements were an ion-selective membranes composed of highly lipophilic ionophores (Table 1). The GC-PISS was used to determine the concentration of analytes in human sweat, while $\mathrm{Au}-\mathrm{PISS}$ - in human saliva samples [3, 12, 30]. The surfaces of cation-selective electrodes were covered with PEDOT-a conductive polymer deposited during electrochemical synthesis [31]. The reference electrode was prepared by the $\mathrm{KCl}$ dispersion in the vinyl acetate. RE was fabricated with the use of silver wire electrochemically covered with $\mathrm{AgCl}$.

Next, the wire was placed in a potassium chloride and polyvinyl alcohol mixture and then underwent photocuring reaction using a 2,2-dimethoxy-2-phenylacetophenone (DMPA) as a photoinitiator. The detailed procedure has been presented by Urbanowicz et al. in [3, 12]. In measurements, the Precision Electrochemistry EMF 16 Interface Lawson
Labs Inc. connected to a computer with EMF Suite 2.0 software was used.

\section{Calibration method}

The measurements in samples of human body fluids require taking into account its ionic strength. Therefore, a novel calibration procedure involving abovementioned parameter was developed. Initially, the PISSs were calibrated with the use of solutions consisting of equal concentrations of determined ions (Fig. 2). On the basis of the determined mean sample's ionic strength, the ionic compositions of the calibration solutions for ion-selective sensors were determined.

The ISEs as a part of the PISS were calibrated using three procedures: (1) classical calibration with solutions consisting of only chloride salt of determined ion; (2) multianalyte calibration, with the use of solutions containing salts: $\mathrm{NaCl}, \mathrm{KCl}$, $\mathrm{CaCl}_{2}, \mathrm{MgCl}_{2}$, and $\mathrm{KSCN}$ at the concentration of $0.1 \mathrm{~mol}$ $\mathrm{dm}^{-3}$ that were diluted in the concentration range of $10^{-1}$ $10^{-7} \mathrm{~mol} \mathrm{dm}^{-3}$; (3) multianalyte calibration using designed calibration solutions with constant ionic strength.

A comparison of the abovementioned methods of calibration in relation to the real sample of body fluid, which was human saliva, basing on the literature on the ionic composition of human saliva, the calibration solutions for (3) method was modelled [32]. The model was developed using the Debye-Hückel's equation and Visual Minteq ver. 3.1 software.

The algorithm that was used to mathematically model the composition of calibration solutions for multianalyte calibration techniques is shown in Fig. 3. The input data needed to run the algorithm include the average ionic sample composition consisting of $n$ types of main and $N$ types of interfering ions. In the first stage, $j$-th interfering ion and $i$-th ISE are selected. The next step is to calculate the required selectivity coefficient Eq. (5) and experimental determination of this parameter for the used ISE. Knowledge of the $K_{\mathrm{ij}}{ }^{\text {pot }}$ (req) and $K_{\mathrm{ij}}{ }^{\text {pot }}$ parameters allows for their comparison and a decision to check the condition for another ISE or use it for testing. After selecting $n$ ISEs, the second part of the algorithm includes determining the mean ionic strength of the sample $I_{\text {sample }}$ Eq. (4) and the approximate composition of the calibration solution not in conflict with the selectivity coefficient.
Table 1 Composition of ionselective membranes

\begin{tabular}{lllll}
\hline Ion & Ionophore wt $\%$ & Lipophilic salt wt\% & PVC wt $\%$ & Plasticizer wt\% \\
\hline $\mathrm{Na}^{+}$ & 1.28 & 0.22 & 32.88 & 65.62 \\
$\mathrm{~K}^{+}$ & 1.12 & 0.54 & 33.22 & 65.12 \\
$\mathrm{Ca}^{2+}$ & 1.29 & 0.41 & 33.22 & 65.08 \\
$\mathrm{Mg}^{2+}$ & 1.31 & 0.64 & 32.70 & 65.35 \\
$\mathrm{SCN}$ & 2.22 & - & 32.95 & 64.83 \\
$\mathrm{Cl}^{-}$ & - & 7.63 & 25.88 & 66.49 \\
$\mathrm{H}^{+}$ & 1.15 & 0.58 & 32.94 & 65.33
\end{tabular}


Fig. 1 PISS consist of gold electrodes (a) and glassy carbon electrodes (b)

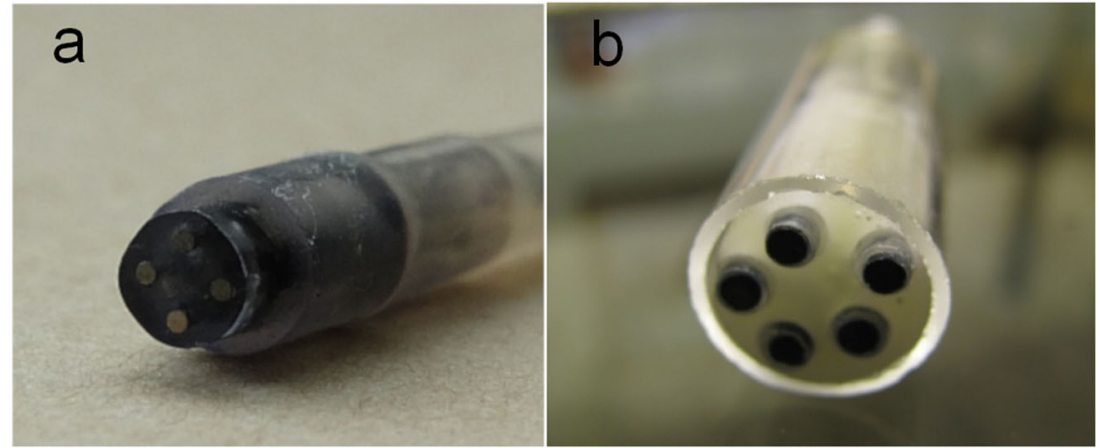

Based on the estimated composition of the calibration solution

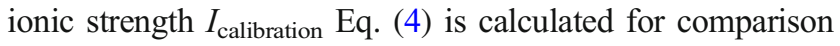
with the $I_{\text {sample }}$ value. In case when both values are convergent, the theoretical composition of the calibration solution dedicated to the sample was obtained. If both values do not coincide, the estimation of the calibration solution composition should be repeated.

In our research, the modeled mean ionic strength of the saliva sample was $I=0.0298 \mathrm{~mol} \mathrm{dm}^{-3}$, and referring to this
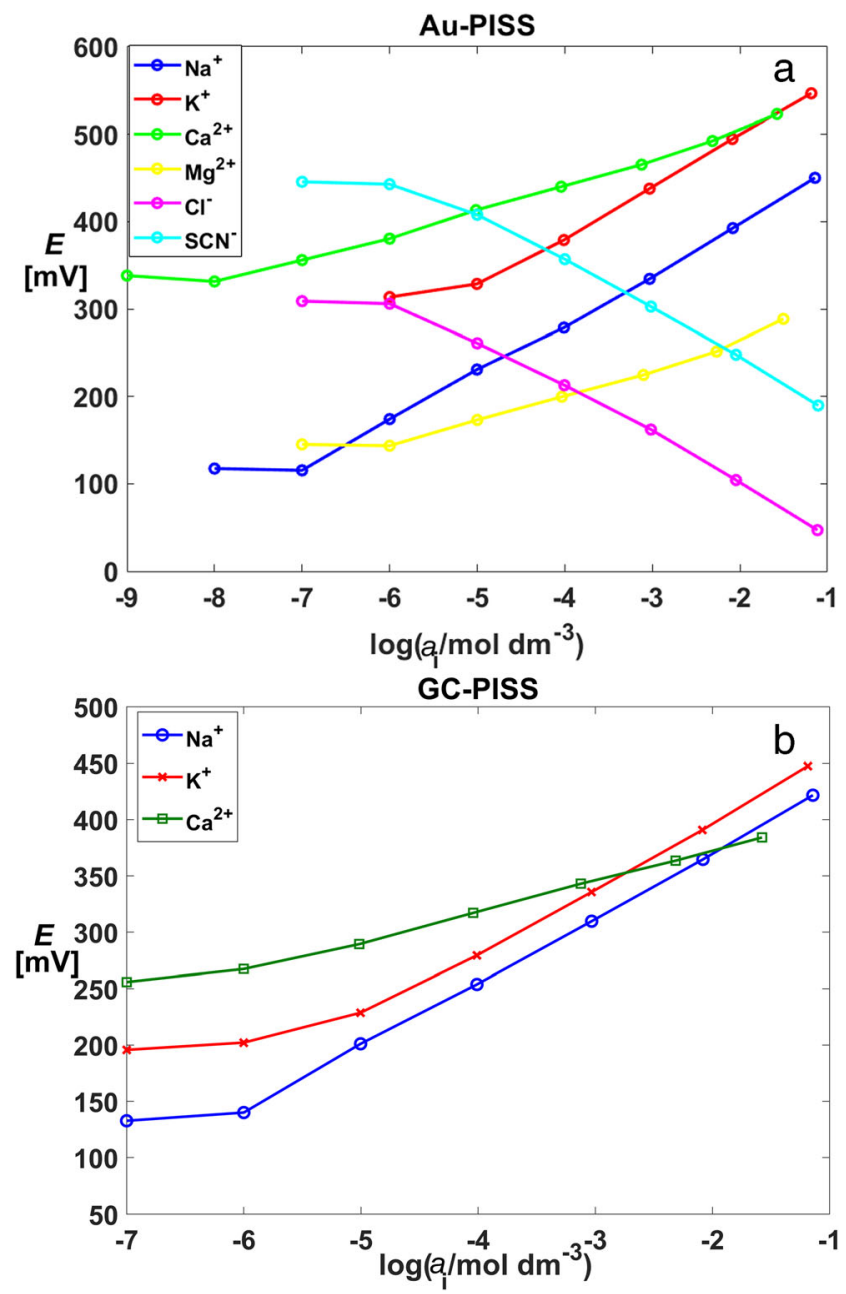

Fig. 2 PISS consist of gold electrodes (a) and glassy carbon electrodes (b) value, a fit of two calibration solutions composition (calibration solutions 1 and 2, respectively) was performed taking into account the maintenance of the constant ionic strength and the required concentration range during the calibration. The compositions of both solutions were selected in the following way: (a) calibration solution 1 consisted of: $10 \mathrm{mmol} \mathrm{dm} \mathrm{dm}^{-3}$, $15 \mathrm{mmol} \mathrm{dm}^{-3} \mathrm{~K}^{+}, 0.5 \mathrm{mmol} \mathrm{dm}{ }^{-3} \mathrm{Ca}^{2+}, 0.1 \mathrm{mmol} \mathrm{dm}{ }^{-3}$ $\mathrm{Mg}^{2+}, 5 \mathrm{mmol} \mathrm{dm}{ }^{-3} \mathrm{SCN}^{-}, 11.2 \mathrm{mmol} \mathrm{dm}{ }^{-3} \mathrm{Cl}^{-}, 4 \mathrm{mmol}$ $\mathrm{dm}^{-3} \mathrm{Li}^{+}, 14 \mathrm{mmol} \mathrm{dm}{ }^{-3} \mathrm{C}_{2} \mathrm{H}_{3} \mathrm{OO}^{-}$, with the resulting ionic strength equaled $I=0.303 \mathrm{~mol} \mathrm{dm}^{-3}$; (b) calibration solution 2 consisted of: $1 \mathrm{mmol} \mathrm{dm} \mathrm{Na}^{-3}, 21 \mathrm{mmol} \mathrm{dm} \mathrm{K}^{-3}, 2 \mathrm{mmol}$ $\mathrm{dm}^{-3} \mathrm{Ca}^{2+}, 1 \mathrm{mmol} \mathrm{dm}{ }^{-3} \mathrm{Mg}^{2+}, 0.5 \mathrm{mmol} \mathrm{dm}^{-3} \mathrm{SCN}^{-}, 26 \mathrm{mmol}$ $\mathrm{dm}^{-3} \mathrm{Cl}^{-}, 0 \mathrm{mmol} \mathrm{dm}{ }^{-3} \mathrm{Li}^{+}, 1 \mathrm{mmol} \mathrm{dm}{ }^{-3} \mathrm{C}_{2} \mathrm{H}_{3} \mathrm{OO}^{-}$, with the resulting ionic strength equaled $I=0.303 \mathrm{~mol} \mathrm{dm}^{-3}$. In particular, the use of lithium and acetate salts allowed to maintain the constant ionic strength of calibration solutions and required concentration ranges for the determination of ions concentration in human saliva. To maintain a constant ionic strength of calibration solutions, the $\mathrm{Li}^{+}$ions have been used due to their low interference in the measurements with primary ions: $\mathrm{Na}^{+}, \mathrm{K}^{+}, \mathrm{Ca}^{2+}$, and $\mathrm{Mg}^{2+}$ present in human body fluids.

\section{Influence of dynamic viscosity on potentiometric response of ISEs}

Due to the fact that samples in the clinical analysis originated from body fluids, an experiment was planned to verify the effect of dynamic viscosity on the metrological parameters of ISEs. In the research, the dynamic viscosity characteristic for whole blood was established as the critical due to its highest value among the dynamic viscosity of body fluids including saliva.

In order to check the effect of solution viscosity on the ISE response, a calibration solution containing $39 \%$ of glycerol of viscosity close to the full blood viscosity were prepared.

\section{ISE lifetime}

The so-called ISE lifetime is a parameter that describes the ability of the electrode to preserve its measuring 


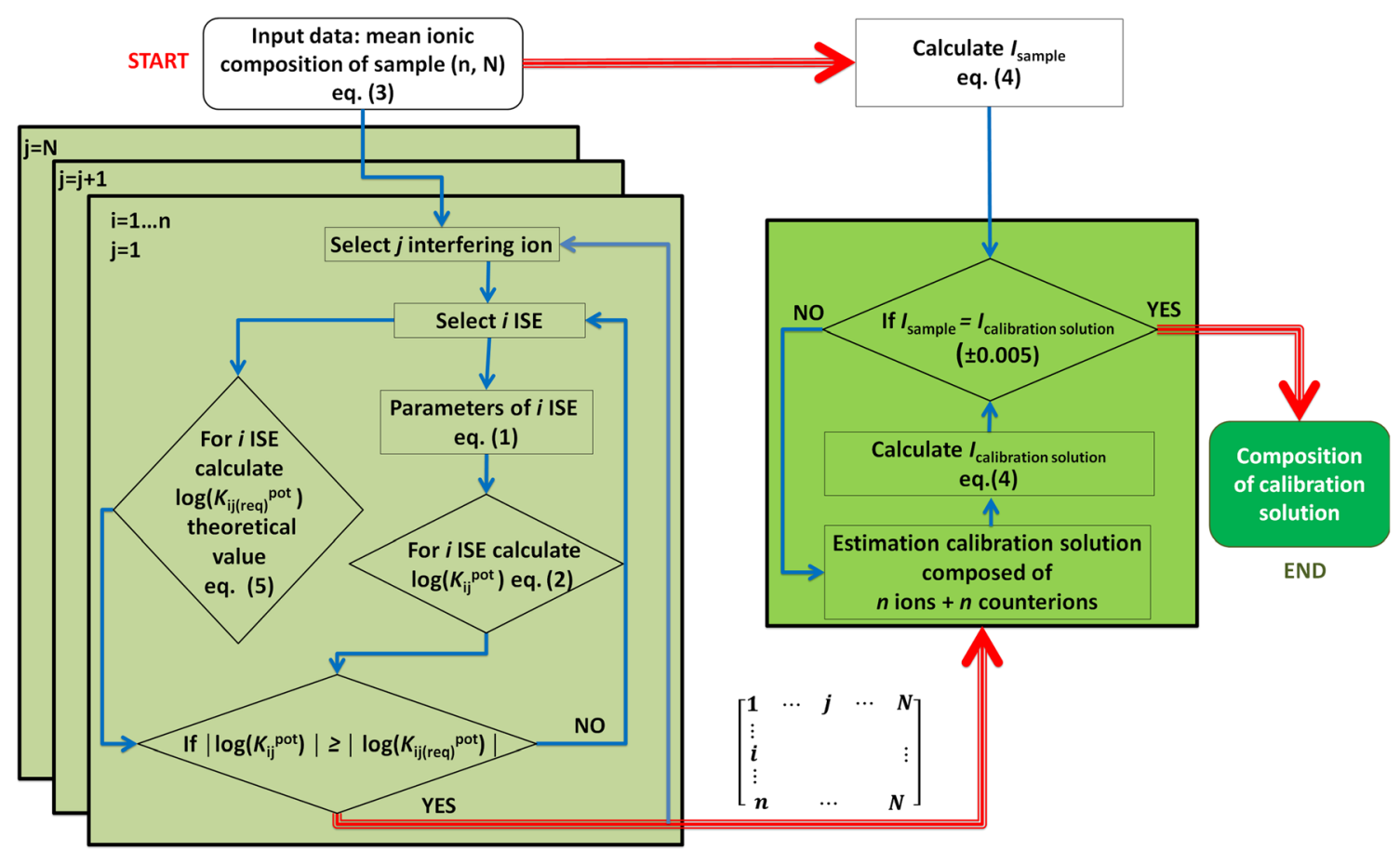

Fig. 3 A schematic representation of the algorithm defining a mathematical model for determining the multi-ionic composition of the calibration solution for ISEs

properties over time. The medical standard referring to the time of ISE use in professional medical analyzers is 3 months of trouble-free work. After this period, regardless of the repeatability of their work, ISEs are exchanged for new sensors. This procedure is related to the statistical standardization of the device in terms of the optimal ISE lifetime which may vary depending on the applied electrode technology and the composition of the ion selective membrane. In order to examine individual parameters of the sensors, a series of solid contact ISEs with the use of glassy carbon (GC) were constructed.

After covering GC with the conductive PEDOT polymer (excluding ISE sensitive to anions), a previously prepared solution of ion selective membrane was applied to the surfaces of the electrodes. After ISE conditioning and rinsing with deionised water, a series of tests were carried out to determine the basic parameters such as $E M F$ characteristics of electrodes, linear range, limit of detection, and sensitivity and selectivity coefficient (determined by SSM and FIM). The whole experiment was carried out: daily during the first 5 days of testing, every week until the end of first month of testing, and finally once a month since the beginning of the second month until the ISE lifetime-each time determining the abovementioned ISE parameters. After each series of tests carried out the ISE were vigorously rinsed with deionised water and stored for the next test in a conditioning solution.

\section{Results}

\section{Evaluation of calibration methods}

On the basis of the performed ISEs calibrations, it was shown that all sensors exhibited Nernst's response (Table 2, Fig. 2), regardless of the calibration method being used. In order to compare the effectiveness of the calibration, samples of human saliva were collected and centrifuged. Samples were used to determine the concentration of selected analytes. Each measurement was preceded by calibration with the use of particular calibration methods, starting from the classical one and finishing on the method utilizing solutions of constant ionic strength.

Table 3 shows the comparison of the results obtained with the use of Au-PISS and the reference methods such as flame photometry, UV-Vis spectrophotometry, and direct

Table 2 Parameter of ISEs included in PISS

\begin{tabular}{lll}
\hline ISE & $S[\mathrm{mV} / \mathrm{dec}]$ & Linear range**-log$(a)$ \\
\hline $\mathrm{Na}^{+}$ & $56.3 \pm 1.0$ & $1-7$ \\
$\mathrm{~K}^{+}$ & $58.3 \pm 0.8$ & $1-5$ \\
$\mathrm{Ca}^{2+}$ & $29.2 \pm 0.9$ & $1-8$ \\
$\mathrm{Mg}^{2+}$ & $30.0 \pm 0.5$ & $1-6$ \\
$\mathrm{Cl}^{-}$ & $-53.9 \pm 2.0$ & $1-6$ \\
$\mathrm{SCN}^{-}$ & $-53.4 \pm 2.3$ & $1-6$ \\
$\mathrm{pH}$ & $60.6 \pm 0.9$ & $5-11$ \\
\hline
\end{tabular}


Table 3 The result of measurements using different $\mathrm{Au}-$ PISS calibration technique

\begin{tabular}{|c|c|c|c|c|}
\hline \multirow[t]{2}{*}{ Ion } & \multicolumn{4}{|l|}{ Method } \\
\hline & $\begin{array}{l}\text { Classic } \\
c\left[\mathrm{mmol} / \mathrm{dm}^{3}\right]\end{array}$ & Multianalyte & Constant ionic strength & Reference method \\
\hline \multicolumn{5}{|c|}{ Sample 1} \\
\hline $\mathrm{Na}^{+}$ & 6.18 & 6.06 & 5.61 & $5.48[\mathrm{c}]$ \\
\hline $\mathrm{K}^{+}$ & 17.15 & 16.61 & 15.98 & $15.75[\mathrm{c}]$ \\
\hline $\mathrm{Ca}^{2+}$ & 1.36 & 1.30 & 1.22 & $1.15[\mathrm{c}]$ \\
\hline $\mathrm{Mg}^{2+}$ & 0.47 & 0.45 & 0.42 & $0.38[\mathrm{a}]$ \\
\hline $\mathrm{SCN}$ & 30.6 & 31.35 & 27.78 & $25.64[\mathrm{~b}]$ \\
\hline $\mathrm{Cl}^{-}$ & 2.02 & 2.06 & 1.88 & $1.75[\mathrm{c}]$ \\
\hline $\mathrm{H}^{+}$ & 7.66 & 7.60 & 7.18 & $7.02[\mathrm{c}]$ \\
\hline \multicolumn{5}{|c|}{ Sample 2} \\
\hline $\mathrm{Na}^{+}$ & 6.81 & 6.68 & 6.18 & $6.03[\mathrm{c}]$ \\
\hline $\mathrm{K}^{+}$ & 17.25 & 16.71 & 16.07 & $15.83[\mathrm{c}]$ \\
\hline $\mathrm{Ca}^{2+}$ & 1.30 & 1.24 & 1.16 & $1.09[\mathrm{c}]$ \\
\hline $\mathrm{Mg}^{2+}$ & 0.63 & 0.61 & 0.56 & $0.51[\mathrm{a}]$ \\
\hline $\mathrm{SCN}$ & 31.09 & 31.85 & 28.18 & $25.98[\mathrm{~b}]$ \\
\hline $\mathrm{Cl}^{-}$ & 2.78 & 2.83 & 2.58 & $2.4[\mathrm{c}]$ \\
\hline $\mathrm{H}^{+}$ & 8.76 & 8.69 & 8.21 & $8.02[\mathrm{c}]$ \\
\hline \multicolumn{5}{|c|}{ Sample 3} \\
\hline $\mathrm{Na}^{+}$ & 5.56 & 5.45 & 5.05 & $4.93[\mathrm{c}]$ \\
\hline $\mathrm{K}^{+}$ & 16.82 & 16.30 & 15.68 & $15.45[\mathrm{c}]$ \\
\hline $\mathrm{Ca}^{2+}$ & 1.16 & 1.11 & 1.04 & 0.98 [c] \\
\hline $\mathrm{Mg}^{2+}$ & 1.32 & 1.28 & 1.19 & $1.08[\mathrm{a}]$ \\
\hline $\mathrm{SCN}$ & 30.31 & 31.04 & 27.51 & $25.38[\mathrm{~b}]$ \\
\hline $\mathrm{Cl}^{-}$ & 2.38 & 2.43 & 2.22 & $2.06[\mathrm{c}]$ \\
\hline $\mathrm{H}^{+}$ & 6.93 & 6.87 & 6.50 & $6.35[\mathrm{c}]$ \\
\hline
\end{tabular}

Reference methods were [a] flame photometry, [b] UV-Vis spectrophotometry and [c] direct potentiometry (Radiometer ABL flex 800 - clinical analyzer) potentiometry (Radiometer ABL flex 800 - clinical analyzer), wherein the measurements were performed separately for each individual analyte. In further considerations, the results obtained with the use of Au-PISS, which were calibrated with particular calibration methods, were referred to the reference value obtained by reference method and expressed as a percentage.

Fig. 4 Percentage difference in the concentration of selected ions in human saliva, determined by means of Au-PISS with the use of various calibration techniques, related to the reference method
In order to compare the differences resulting from the utilization of various calibration methods, selected ions in human saliva were determined. Each measurement was preceded by means of different calibration procedures: (1) classical with a solution containing only the measured ion (calibration 2, blue bar); (2) multianalyte calibration in a wide concentration range (calibration 3 , green bar);








Fig. 5 Calibration curves for $\mathrm{Na}^{+}, \mathrm{K}^{+}$, and $\mathrm{Ca}^{2+}$ selective electrodes determined using 39\% glycerol solutions. Parameters of the electrodes in Table 4

(3) calibration in a narrow concentration range with the use of solutions of constant ionic strength (calibration 1, red bar). The results of the percentage of the sensors response versus reference method are shown in Fig. 4. The observations concerning the influence of the calibration method on the differences of the determination of the analytes' concentration, using ion-selective electrodes being a part of Au-PISS, showed that the results obtained after calibration with the use of solutions of constant ionic strength in a narrow range, are the closest to the reference values.

Referring the results to the reference values for the concentration of individual ions, the largest relative error was observed for the measurements of divalent cations $\left(\mathrm{Ca}^{2+}\right.$ and $\left.\mathrm{Mg}^{2+}\right)$ and anions $\left(\mathrm{Cl}^{-}\right.$and $\left.\mathrm{SCN}^{-}\right)-106-$ $122 \%$. The lowest errors were noted for measurements of monovalent cations: $\mathrm{Na}^{+}$and $\mathrm{K}^{+}$. The comparison of the different calibration methods showed that the utilization of narrow concentration ranges together with the constant ionic strength of the calibration solutions brought a positive effect in reducing the relative measurement error for electrodes selective on: $\mathrm{Na}^{+} 8-10 \%, \mathrm{~K}^{+} 4-8 \%, \mathrm{Ca}^{2+}$ $7-12 \%, \mathrm{Mg}^{2+} 8-12 \%, \mathrm{Cl}^{-} 10-13 \%, \mathrm{SCN}^{-} 8-10 \%$, and $\mathrm{pH}$ 6-7\%. The largest errors were obtained during the determination of cations' concentration preceded with the
Table 5 Comparison of the GC-ISEs selectivity coefficients in a 39\% glycerol solution

\begin{tabular}{llll}
\hline \multirow{2}{*}{ ISE } & \multicolumn{3}{l}{ Selectivity coefficient $\mathrm{SSM}^{*} \log \left(K_{\mathrm{ij}}{ }^{\text {pot }}\right)$} \\
\cline { 2 - 4 } & $\mathrm{Na}^{+}$ & $\mathrm{K}^{+}$ & $\mathrm{Ca}^{2+}$ \\
\hline $\mathrm{Na}^{+}$ & - & $-2.8 \pm 0.1$ & $-4.9 \pm 0.1$ \\
$\mathrm{~K}^{+}$ & $-3.2 \pm 0.1$ & - & $-5.2 \pm 0.1$ \\
$\mathrm{Ca}^{2+}$ & $-5.2 \pm 0.1$ & $-5.9 \pm 0.1$ & - \\
& $\mathrm{Selectivity} \mathrm{coefficient} \mathrm{SSM}^{* *} \log \left(K_{\mathrm{ij}}{ }^{\text {pot }}\right)$ & \\
& $\mathrm{Na}^{+}$ & $\mathrm{K}^{+}$ & $\mathrm{Ca}^{2+}$ \\
$\mathrm{Na}^{+}$ & - & $-2.9 \pm 0.1$ & $-5.0 \pm 0.1$ \\
$\mathrm{~K}^{+}$ & $-3.3 \pm 0.1$ & - & $-5.3 \pm 0.1$ \\
$\mathrm{Ca}^{2+}$ & $-5.3 \pm 0.1$ & $-5.7 \pm 0.1$ & - \\
\hline$*$ calibration in water; ${ }^{* *}$ calibration in glycerol solutions
\end{tabular}

classical calibration, as well as anions' concentration determination preceded by multianalyte calibration.

\section{ISEs parameters versus high viscosity}

The studies were performed using electrodes based on glassy carbon covered by PEDOT with membranes selective for $\mathrm{Na}^{+}, \mathrm{K}^{+}$, and $\mathrm{Ca}^{2+}$ ions, which were prepared in accordance with the protocol presented in the material and methods chapter. The calibration solutions were 39\% aqueous solutions of glycerol, containing adequate concentrations of chloride sodium, potassium, and calcium salts. The results of the measurements were used to determine the selectivity coefficients using the separate solution method (SSM).

The slope of the calibration curves (Fig. 5 and Table 4) was consistent with the Nernst model. In contrast, the linear range of electrode work was narrower, which may suggest the effect of the viscosity of the solution on the potentiometric ISE response. The selectivity coefficients (Table 5) were comparable to those obtained for aqueous solutions. The probable reason for decreasing of sensors linear range was the difficult transport of ions at the solution-membrane interface, which resulted from the increased viscosity of the medium. In addition, glycerol may adversely affect the leaching and conditioning of the ion-selective membrane but will not affect the
Table 4 Electrode characteristics using $39 \%$ glycerol solutions

\begin{tabular}{lcccccc}
\hline ISE & $S^{*}[\mathrm{mV} / \mathrm{dec}]$ & $\begin{array}{c}\text { Linear range } \\
-\log (a)\end{array}$ & $E^{0^{*}}[\mathrm{mV}]$ & $S^{* *}[\mathrm{mV} / \mathrm{dec}]$ & $\begin{array}{l}\text { Linear range** } \\
-\log (a)\end{array}$ & $E^{0^{* *}}[\mathrm{mV}]$ \\
\hline $\mathrm{Na}^{+}$ & $56.9 \pm 1.4$ & $1-6$ & $609 \pm 3$ & $55.2 \pm 1.1$ & $1-5$ & $612 \pm 5$ \\
$\mathrm{~K}^{+}$ & $59.4 \pm 0.1$ & $1-5$ & $524 \pm 1$ & $59.6 \pm 0.6$ & $1-4$ & $521 \pm 2$ \\
$\mathrm{Ca}^{2+}$ & $28.4 \pm 2.1$ & $1-6$ & $455 \pm 6$ & $25.8 \pm 1.2$ & $1-4$ & $451 \pm 8$ \\
\hline
\end{tabular}

* calibration in water; ${ }^{* *}$ calibration in glycerol solutions 



Fig. $6 \mathrm{Na}^{+}, \mathrm{K}^{+}, \mathrm{Ca}^{2+}, \mathrm{Mg}^{2+}$, and $\mathrm{Cl}^{-}$ISEs characteristics in time. Data on the sensitivity and $E^{0}$ potential are presented in Table 6

selectivity of the used sensors. The aqueous glycerol solution does not significantly affect the structure of the ion-selective membrane, but it influences the ion-ion interaction in the solution itself, which has an indirect effect on the ISE response [33]. Considering the abovementioned observations, and the fact that the changes of sensors sensitivity were small, and although the measuring range was narrowed; nevertheless it did not constitute a barrier to their applications in body fluids analysis. Therefore it was decided that the calibration of the sensors will be carried out in aqueous solutions.

\section{ISE lifetime}

Mechanical damage, the membrane defects, the type of plasticizer, and ionophore have a significant influence on the ionselective sensors lifetime. Theoretical models and calculations based on lipophilicity show that the ion-selective electrodes 
Table 6 Long-term sensitivity fluctuations of ISE and $\mathrm{E}^{0}$ stability. See Fig. 6

\begin{tabular}{lllllll}
\hline ISE & ISE lifetime [month] & \multicolumn{2}{l}{$S_{\text {mean }}[\mathrm{mV} / \mathrm{dec}]$} & \multirow{2}{*}{$E^{0}[\mathrm{mV}]$} \\
\cline { 3 - 6 } & & {$[\mathrm{A}]$} & {$[\mathrm{B}]$} & {$[\mathrm{C}]$} & {$[\mathrm{D}]$} & \\
\hline $\mathrm{Na}^{+}$ & 7 & $59.8 \pm 1.6$ & $59.7 \pm 0.9$ & $58.2 \pm 2.3$ & $60.7 \pm 1.4$ & $255 \pm 7$ \\
$\mathrm{~K}^{+}$ & 7 & $59.0 \pm 0.9$ & $59.4 \pm 1.1$ & $59.1 \pm 1.4$ & $58.6 \pm 0.4$ & $449 \pm 3$ \\
$\mathrm{Ca}^{2+}$ & 7 & $27.3 \pm 1.9$ & $25.9 \pm 1.2$ & $27.1 \pm 3.3$ & $28.3 \pm 1.2$ & $392 \pm 9$ \\
$\mathrm{Mg}^{2+}$ & 3 & $30.9 \pm 1.7$ & $30.7 \pm 1.4$ & $32.1 \pm 0.5$ & $30.2 \pm 2.8$ & $180 \pm 24$ \\
$\mathrm{Cl}^{-}$ & 2 & $-56.3 \pm 2.3$ & $-54.8 \pm 2.3$ & $-56.9 \pm 0.8$ & $-59.1 \pm 0.7$ & $-131 \pm 6$ \\
\hline
\end{tabular}

lifetime should be at least 1 month [15]. The tests were carried out using single electrodes made of glassy carbon, which were prepared in accordance with the protocol presented in the material and methods chapter. The aim of this part of the research was to verify the ISE lifetime.

Figure 6 shows results of long-term ISE measurements. In the case of a sodium ion-sensitive electrode, a progressive decrease in the linear range is visible. In the first week of the study, the limit of detection was at the level of $\log (a)=-7$, then decreased to values of -6 and -5 .

The electrodes sensitive to potassium ions were the sensors with the highest stability. Throughout the experiment, the limit of detection was stable at $\log (a)=-5$. For ISE sensitive to $\mathrm{Na}^{+}$and $\mathrm{K}^{+}$ions, the lifetime was estimated to be about 7 months. ISEs selective for divalent cations have different durability. In the case of ISE selective to calcium ions, the time of correct and repeatable work was the same as for $\mathrm{Na}^{+}$and $\mathrm{K}^{+}$ ISEs, while the electrode sensitive to magnesium ions functioned for about 3 months. There are significant deviations in the EMF characteristics of these electrodes, which occurred, for example, in the fifth month of the study. The shortest life

Table 7 Long-term selectivity coefficients for ISE determined by SSM and FIM method.

\begin{tabular}{|c|c|c|c|c|}
\hline \multirow[t]{2}{*}{ ISE } & \multicolumn{4}{|c|}{ Selectivity coefficient SSM $\log \left(K_{\mathrm{ij}}^{\mathrm{pot}}\right)$} \\
\hline & $\mathrm{Na}^{+}$ & $\mathrm{K}^{+}$ & $\mathrm{Ca}^{2+}$ & $\mathrm{Mg}^{2+}$ \\
\hline $\mathrm{Na}^{+}$ & - & $-2.8 \pm 0.1$ & $-2.5 \pm 0.1$ & $-5.1 \pm 0.2$ \\
\hline $\mathrm{K}^{+}$ & $-4.0 \pm 0.1$ & - & $-4.9 \pm 0.1$ & $-5.3 \pm 0.1$ \\
\hline $\mathrm{Ca}^{2+}$ & $-5.2 \pm 0.1$ & $-6.9 \pm 0.2$ & - & $-4.1 \pm 0.1$ \\
\hline \multirow[t]{2}{*}{$\mathrm{Mg}^{2+}$} & $-3.6 \pm 0.1$ & $-3.5 \pm 0.1$ & $-0.1 \pm 0.1$ & - \\
\hline & $\mathrm{HCO}_{3}^{-}$ & $\mathrm{SO}_{4}{ }^{2-}$ & $\mathrm{NO}_{3}^{-}$ & $\mathrm{HPO}_{4}{ }^{2-}$ \\
\hline $\mathrm{Cl}^{-}$ & $-2.2 \pm 0.2$ & $-1.2 \pm 0.1$ & $0.4 \pm 0.1$ & $-3.4 \pm 0.1$ \\
\hline \multicolumn{5}{|c|}{ Selectivity coefficient FIM $\log \left(K_{\mathrm{ij}}^{\mathrm{pot}}\right)$} \\
\hline & $\mathrm{Na}^{+}$ & $\mathrm{K}^{+}$ & $\mathrm{Ca}^{2+}$ & $\mathrm{Mg}^{2+}$ \\
\hline $\mathrm{Na}^{+}$ & - & $-3.0 \pm 0.2$ & $-2.5 \pm 0.1$ & $-5.0 \pm 0.2$ \\
\hline $\mathrm{K}^{+}$ & $-4.1 \pm 0.1$ & - & $-4.7 \pm 0.2$ & $-5.5 \pm 0.2$ \\
\hline $\mathrm{Ca}^{2+}$ & $-5.0 \pm 0.1$ & $-6.7 \pm 0.3$ & - & $-3.9 \pm 0.1$ \\
\hline \multirow[t]{2}{*}{$\mathrm{Mg}^{2+}$} & $-3.7 \pm 0.1$ & $-3.6 \pm 0.2$ & $-0.0 \pm 0.1$ & - \\
\hline & $\mathrm{HCO}_{3}^{-}$ & $\mathrm{SO}_{4}{ }^{2-}$ & $\mathrm{NO}_{3}^{-}$ & $\mathrm{HPO}_{4}{ }^{2-}$ \\
\hline $\mathrm{Cl}^{-}$ & $-2.3 \pm 0.2$ & $-1.1 \pm 0.1$ & $0.5 \pm 0.1$ & $-3.4 \pm 0.1$ \\
\hline
\end{tabular}

time had the ISE selective for chloride ions. After 2 months, its parameters deteriorated to a degree that precluded further measurements. A possible reason was mechanical failure of the membrane (the membrane was detached from the electrodes' surface). Changes in the mean sensitivity $\left(S_{\text {mean }}\right)$ of the ISE during the long-term test are presented in the Table 6 . The biggest changes can be observed for ISE selective to divalent ions. The most stable was the electrode based on valinomycin. The potential $E^{0}$ stability was the highest for potassium-selective sensor, while the lowest for the Mg-ISE. The probable reason for the large drift of $E^{0}$ potential was the use of chloroparaffin as a plasticizer in the magnesiumselective membrane. Membranes composed of chloroparaffin are characterized by lower elasticity and ease of detachment of electrode surface, which can have a direct influence on ISEs durability and stability.

In terms of electrode functionality, the most important parameter is their selectivity to interfering ions. Table 7 presents the selectivity coefficients obtained by the SSM and FIM method determined during the whole experiment.

The calculated values of $\log \left(K_{\mathrm{ij}}{ }^{\text {pot }}\right)$ were described in another article $[3,12]$ and corresponded to IUPAC standard values [34]. The calculated standard deviation for the selectivity coefficients was small, which indicates that the sensors were according to reproducible procedure.

\section{Conclusions}

The obtained results indicated that the applied calibration procedure influence the difference between the expected and the measured value of the selected analytes. The most effective calibration method was based on solutions of the constant ionic strength. The developed calibration solutions were utilized to calibrate ion-selective sensors, which were subsequently used to determine the concentration of selected ions in the human saliva. The implementation of the method, including the use of multianalyte calibration solutions that maintain constant ionic strength, allowed to (1) minimize the measurement relative error; (2) reduce consumption of calibration solutions, necessary for the calibration of each particular sensor; and (3) simultaneously calibrate the sensors sensitive to 
different analytes. One of the main benefits of the proposed calibration method is the possibility of using this technique for simultaneous calibration of integrated ion-selective sensors that are sensitive to various analytes. Moreover, tests have been carried out to check the effect of the viscosity of the test solution on the ISE linear range, which showed that the increased viscosity limits the scope of ion-selective sensors but does not affect their selectivity. In addition, the lifetime of ISE made from glassy carbon has been tested. The most durable and stabile ISE was a sensor with the potassium ions selective membrane, which worked throughout the duration of the experiment without changes in metrological parameters. The research suggests that an important element in the design of ion-selective electrodes is knowledge about the tested samples. Thanks to the knowledge of the sample composition, it is possible to propose dedicated calibration solutions. Consideration of rheological properties of the sample such as viscosity may be crucial when the analytes being measured is at a low concentration level, which does not include the linear range of the sensor response.

Funding information We gratefully acknowledge the partial financial support (DS 030893) from Gdańsk University of Technology, Gdańsk 80-233, PL.

Open Access This article is distributed under the terms of the Creative Commons Attribution 4.0 International License (http:// creativecommons.org/licenses/by/4.0/), which permits unrestricted use, distribution, and reproduction in any medium, provided you give appropriate credit to the original author(s) and the source, provide a link to the Creative Commons license, and indicate if changes were made.

\section{References}

1. Lewenstam A (2014) Electroanalysis 26(6):1171-1181

2. Mousavi Z, Granholm K, Sokalski T, Lewenstam A (2015) Sensors Actuators B 207:895-899

3. Jasiński A, Urbanowicz M, Guziński M, Bocheńska M (2015) Electroanalysis 27(3):745-751

4. Yin T, Pan D, Qin W (2014) Anal Chem 86(22):11038-11044

5. Bobacka J, Ivaska A, Lewenstam A (2008) Chem Rev 108(2):329338

6. Lewenstam A, Bobacka J, Ivaska A (1994) J Electroanal Chem 23: 23-28

7. Oyama N, Hirokawa T, Yamaguchi S, Ushizawa N, Shimomura T (1987) Anal Chem 59(2):258-264
8. Guzinski M, Jarvis JM, D’Orazio P, Izadyar A, Pendley BD, Lindner E (2017) Anal Chem 89(16):8468-8475

9. Cui J, Lisak G, Strzalkowska S, Bobacka J (2014) Analyst 139(9): 2133-2136

10. Blaz T, Baś B, Kupis J, Migdalski J, Lewenstam A (2013) Electrochem Commun 34:181-184

11. Lindner E, Pendley BD (2013) Anal Chim Acta 762:1-13

12. Urbanowicz M, Jasiński A, Jasińska M, Drucis K, Ekman M, Szarmach A, Suchodolski R, Pomećko R, Bocheńska M (2017) Electroanalysis 29(10):2232-2238

13. Mohan MS, Bates G (1975) Clin Chem 21(7):864-872

14. Baret M, Massart DL, Fabry P, Conesa F, Eichner C, Menardo C (2000) Talanta 51(5):863-877

15. Oesch U, Ammann D, Simon W (1986) Clin Chem 32:1448-1459

16. Horvai G, Toth K, Pungor E (1976) Anal Chim Acta 82(1):45-54

17. Sáez de Viteri FJ, Diamond D (1994) Analyst 119(5):749-758

18. Beebe KR, Kowalski BR (1988) Anal Chem 60(20):2273-2278

19. Lisak G, Ivaska A, Lewenstam A, Bobacka J (2014) Electrochim Acta 140:27-32

20. Lisak G, Arnebrant T, Lewenstam A, Bobacka J, Ruzgas T (2016) Anal Chem 88(6):3009-3014

21. Joon NK, He N, Wagner M, Cárdenas M, Bobacka J, Lisak G (2017) Electrochim Acta 252:490-497

22. Stokes RH, Robinson RA (1948) J Am Chem Soc 70(5):1870 1878

23. Cammann K (1979) Working with ion-selective electrodes. Springer-Verlag, Berlin

24. Schipper RG, Silletti E, Vingerhoedes MH (2007) Arch Oral Biol 52(12):1114-1135

25. Roberts BJ (1977) J Dent 5(4):303-309

26. Vissink A, Waterman HA, 'S-Gravenmade EJ, Panders AK, Vermay A (1984) J Oral Pathol 13(1):22-28

27. Van Der Reijden WA, Veerman ECI, Van Nieuw Amergongen A (1994) Biorheology 31:631-642

28. Pomećko R, Asfari Z, Hubscher-Bruder V, Bocheńska M, ArnaudNeu F (2010) Supramol Chem 22(5):275-288

29. Pomećko R, Asfari Z, Hubscher-Bruder V, Bocheńska M, ArnaudNeu F (2007) Supramol Chem 7:459

30. Urbanowicz M, Pijanowska DG, Jasiński A, Bocheńska M (2018) XV International scientific conference on optoelectronic and electronic sensors (COE). DOI: https://doi.org/10.1109/COE.2018. 8435148.

31. Guziński M (2013), Dissertation: development of all-solid-state potentiometric measurement system to determine concentration of lead (II) cations, Gdańsk University of Technology, 2013.

32. Aps JKM, Martens LC (2005) Forensic Sci Int 150(2-3):119-131

33. Hosseini M, Ghalami-Choobar B, Zanjanchi M-A (2015) Phys Chem Res 3:305-318

34. Umezawa Y, Buhlmann P, Umezawa K, Tohda K, Amemiya S (2000) Pure and Appl. Chem. 71:1851-2082

Publisher's note Springer Nature remains neutral with regard to jurisdictional claims in published maps and institutional affiliations. 